BMJ Open Sport \& Exercise Medicine

\title{
Mental health among elite athletes in Norway during a selected period of the COVID-19 pandemic
}

\author{
Anne Marte Pensgaard (D) , ${ }^{1}$ Tom Henning Oevreboe (i) , ${ }^{1}$ Andreas Ivarsson (i) ${ }^{2}$
}

\begin{abstract}
To cite: Pensgaard AM, Oevreboe TH, Ivarsson A. Mental health among elite athletes in Norway during a selected period of the COVID-19 pandemic. BMJ Open Sport \& Exercise Medicine 2021;7:e001025. doi:10.1136/ bmjsem-2020-001025
\end{abstract}

Accepted 15 February 2021 (c) Author(s) (or their employer(s)) 2021. Re-use permitted under CC BY-NC. No commercial re-use. See rights and permissions. Published by BMJ.

${ }^{1}$ Department of Sport and Social Sciences, Norwegian School of Sports Sciences, Oslo, Akershus, Norway

${ }^{2}$ Centre of research on Welfare, Health and Sport, School of Health and Social Science, Halmstad, Sweden

Correspondence to Professor Anne Marte Pensgaard; annemp@nih.no

\section{ABSTRACT}

Objective To investigate the prevalence of mental health problems and satisfaction with life among different groups of elite athletes during a selected period of the COVID-19 pandemic and examine how COVID-19 related consequences were associated with these variables.

Design Cross-sectional data collection during a selected period of the COVID-19 pandemic in Norway.

Participants 378 elite athletes, mean age 26.86 (range 18-59), 159 females and 219 males, divided into Olympiclevel and Paralympic-level athletes ( $n=194)$ and elite and semielite athletes $(n=184)$.

Main outcome measures Hopkins Symptoms Check List - 10; symptoms of anxiety and depression; Bergen Insomnia Scale; Eating Disorder Examination Questionnaire Short; Canadian Problem Gambling Index and Satisfaction with Life Scale. In addition, we included specific COVID-19 questions (eg, financial concern, keeping daily routines, perceived coping and motivation).

Results Symptoms of insomnia (38.3\%) and depression $(22.3 \%)$ were most prevalent within the sample. Symptoms of eating disorders more prevalent among female athletes $(8.8 \%$ vs $1.4 \%)$ while symptoms of gambling problems were higher among male athletes (8.6\% vs $1.3 \%$ ). Olympic and Paralympic athletes reported lower levels of anxiety and depression symptoms than elite and semielite athletes. Financial concerns were associated with an increased risk of mental health problems, while daily routines and perception of coping were associated with less mental health problems and higher satisfaction with life.

Conclusion Symptoms of insomnia and depression were the two most common mental health problems reported during this selected phase of the COVID-19 pandemic. Elite and semielite athletes reported financial concerns as a risk factor for mental health problems at a larger degree than Olympic and Paralympic athletes.

\section{INTRODUCTION}

IOC consensus statement from 2019 underscored that symptoms of mental illness are common among elite level athletes, and athletes' mental health must, therefore, be taken seriously. ${ }^{1}$ Since then, the COVID-19 pandemic has hit the world with unforeseen force. Clearly, such unexpected events have the potential to be extremely stressful
What are the new findings

Depression symptoms and insomnia were the two major mental health concerns.

- Financial concerns were associated with more anxiety and depression symptoms and lower satisfaction with life among elite and semielite athletes, while Olympic-level and Paralympic-level athletes who perceived that they coped with the situation reported lower levels of anxiety, depression and insomnia symptoms.

- Keeping daily routines and perceiving positive consequences of the pandemic were associated with less mental health problems and higher satisfaction with life.

What might impact on clinical practice in the future

Financial concern is a major stressor for athletes and should be addressed.

- Helping athletes keep their daily routines is important as well as maintaining a positive outcome expectation.

experiences for people in general and for elite athletes. ${ }^{2}$ Reardon $e t a \hat{l}$ has asked for more insight into how elite athletes perceive and cope with this highly unusual situation because it creates additional strain on elite athletes. Some research has been conducted to gain knowledge about how this group of athletes perceives the situation. During the initial stages of the COVID-19 emergency period, there was an increased levels of symptoms of anxiety and depression in professional footballers; both male and females were reported especially among those worried about their future as players. ${ }^{4}$ Elite athletes from South Africa reported that the COVID-19 situation affected their sleep patterns $(79 \%)$, increased depression (52\%) and disturbed eating patterns $(76 \%) .^{5}$ A web study during the earlier phase of the COVID-19 pandemic period (May-June 2020) among Swedish top leagues in handball, soccer and ice hockey 
showed that $70 \%$ of the female athletes and $40 \%$ of the male athletes felt psychologically slightly worse or worse than before the pandemic. ${ }^{6}$ Among the male athletes, there were also an increased risk of gambling problems $(10 \%)$, while $19 \%$ of female athletes reported increased levels of depression. ${ }^{6}$ To sum up, there are indicators pointing to the fact that the COVID-19 situation is taking its toll on elite athletes' mental health. To gain a more extensive knowledge about the responses to this unique situation, it is, however, important to investigate how the athlete's perceptions and experiences of various aspects related to the COVID-19 situation is associated with mental health and well-being. This information can, for example, help in the development of recourses to guide athletes to cope with extreme situations like this.

Thus, the main objective was to investigate the mental health status of elite-level athletes during a specific COVID-19 period. A second aim was to examine how COVID-19 related consequences were associated with mental health problems and reported satisfaction with life. A third aim was to investigate differences in risk factors for mental health between Olympic and Paralympic athletes, compared with elite and semielite athletes.

\section{METHODS}

A cross-sectional online survey, Nettskjema, was distributed to Olympic-level and Paralympic-level athletes, as well as to athletes who were members of The Norwegian Athlete Association (NISO). Data was collected between June 2020 and September 2020. Data were compiled at TSD (Services for sensitive data) at the University of Oslo.

\section{Population}

Of 358 potential athletes from the Olympic and Paralympic sample, 194 athletes completed the survey (response rate $54.19 \%$ ). Of 932 potential elite and semielite athletes (mainly members from NISO's mailing list), we received 184 answers (response rate $19.74 \%$ ) (The Olympic and Paralympic sample includes athletes competing at the highest international level and receive stipendium from the Norwegian Olympic Training Center. The elite and semielite athlete group consists of athletes who compete at a high international level or high national level, but do not receive a stipendium.). There were 159 female and 219 male athletes (Mean=26.86, $\mathrm{SD}=6.13$, range 18-59), who practised on average 16.02 ( $\mathrm{SD}=4.96)$ hours per week. Thirty-nine different sports were represented.

\section{Patient and public involvement}

The Norwegian Athlete Committee was used as consultants of the different versions of the survey.

\section{Measurements}

We used validated Norwegian versions of: the Hopkins Symptoms Check List - 10 (HSCL-10) to measure symptoms of anxiety and depression; The Bergen Insomnia Scale (BIS) to measure insomnia; the Eating Disorder Examination Questionnaire Short (EDE-QS) to measure eating disorders; and the Canadian Problem Gambling Index (CPGI) to measure problems related to gambling. ${ }^{7-10}$ To measure satisfaction with life, the fiveitem Satisfaction with Life Scale (SWLS) was used. ${ }^{11} 12$ In addition, we included selected COVID-19 questions (e,g, economic challenges, motivational status, perceived coping and positive experiences related to COVID-19), derived from the Norwegian COVID-19, Mental Health and Adherence Project. ${ }^{13}$

\section{Data management and statistical analysis}

Before we conducted the analyses, the participants were, based on recommended cut-off scores, for each of the clinical instruments HSCL-10 (for each of the subscales (anxiety and depression) we used the cut-off suggested for the full scale (ie, $\geq 1.85$ )), BIS, EDE-QS and CPGI, coded as 'not at risk' (0) and 'at risk' (1).$^{7-10}$ Descriptive statistics were calculated and presented as frequency for the dichotomous variables and mean accompanied with $\mathrm{SD}$ for the continuous variables.

To compare the frequency of participants at risk for mental health symptoms between males and females as well as between Olympic-level and Paralympic-level athletes compared with elite and semielite level athletes, risk differences accompanied with $95 \%$ CI were calculated. A CI not crossing 0 was considered to indicate a statistically significant difference between groups.

Multivariate binary logistical regression analyses were performed to test the potential association between the participants' experiences of the COVID-19 situation and the risk of different mental health complaints. Separate models were specified for each of the different mental health variables. Age and gender were included as covariates in each of the models. OR together with $95 \%$ CI were calculated for each of the specified independent variables. A CI not including 1 was considered to indicate a statistically significant result. A multivariate linear regression analysis was conducted to investigate the association between the participants' experiences of the COVID-19 situation and perceived satisfaction with life. As a second step, separate binary logistic regression analyses were conducted for Olympic/Paralympic and elite/semielite athletes, respectively.

\section{RESULTS}

\section{Mental health}

The results showed that insomnia $(38.3 \%)$ and depression $(22.3 \%)$ were the two mental health conditions that had the highest numbers of at-risk participants. There was a statistically significant difference between females and males in eating problems (higher risk in females) and gambling problems (higher risk in males). Elite and semielite athletes were, in comparison with Olympic and Paralympic athletes, exposed to an increased at-risk level 
Table 1 Percentages $(95 \% \mathrm{Cl})$ of Norwegian Olympic and Paralympic athletes and elite and semielite athletes with clinical levels of mental health complaints

\begin{tabular}{lccccccc}
\hline & $\begin{array}{l}\text { Total } \\
\text { population } \\
\mathbf{n}=\mathbf{3 7 8}\end{array}$ & $\begin{array}{l}\text { Females } \\
\mathbf{n}=\mathbf{1 5 9}\end{array}$ & $\begin{array}{l}\text { Males } \\
\mathbf{n}=\mathbf{2 1 9}\end{array}$ & $\boldsymbol{\Delta}$ females versus males & $\begin{array}{l}\text { Olympic/para } \\
\mathbf{n}=\mathbf{1 9 4}\end{array}$ & $\begin{array}{l}\text { Elite/semielite } \\
\mathbf{n}=\mathbf{1 8 4}\end{array}$ & $\begin{array}{l}\boldsymbol{\Delta} \text { olympic/para versus } \\
\text { elite/semielite }\end{array}$ \\
\hline Anxiety & 9.3 & 11.3 & 7.8 & $3.5(-2.2$ to 9.4$)$ & 4.6 & 14.1 & $-9.5(-15.3$ to -3.7$)$ \\
Depression & 22.5 & 25.8 & 20.1 & $5.7(-2.7$ to 14.1$)$ & 18.0 & 27.2 & $-9.2(-17.5$ to -0.7$)$ \\
BIS & 38.6 & 42.8 & 35.6 & $7.2(-2.7$ to 17.1$)$ & 34.5 & 42.9 & $-8.4(-18.2$ to 1.4$)$ \\
EDE & 4.5 & 8.8 & 1.4 & $7.4(3.1$ to 11.6$)$ & 4.6 & 4.3 & $0.3(-3.9$ to 4.5$)$ \\
Gambling & 5.6 & 1.3 & 8.7 & $-7.4(-11.9$ to -2.7$)$ & 4.1 & 7.1 & $-3.0(-7.6$ to 1.2$)$ \\
\hline
\end{tabular}

BIS, Bergen Insomnia Scale; EDE, Eating Disorder Examination.

for anxiety and depression symptoms. For more information about prevalence numbers, see table 1.

\section{Associations between experiences of COVID-19 situation and mental health}

The results from the logistic regression analyses showed that worries over the financial situation due to COVID-19 were associated with statistically significant increased risks of anxiety (OR=1.65, 95\% CI 1.09 to 2.49$)$ as well as depressive ( $\mathrm{OR}=1.80,95 \% \mathrm{CI} 1.33$ to 2.45$)$ symptoms.

Also, the results showed that being able to keep daily routines were associated with statistically significant decreased risks of depressive $(\mathrm{OR}=0.53,95 \%$ CI 0.37 to $0.75)$ as well as insomnia (OR=0.66, $95 \%$ CI 0.48 to 0.89$)$ symptoms.

Furthermore, perceived positive consequences related to the COVID-19 situation were associated with decreased risk of symptoms related to eating disorders $(\mathrm{OR}=0.31$, $95 \% \mathrm{CI}=0.15$ to 0.67$)$ and gambling $(\mathrm{OR}=0.52,95 \% \mathrm{CI}$ 0.28 to 0.98$)$. Last, lower levels of motivation due to the COVID-19 situation was associated with an increased risk of insomnia symptoms (OR=1.34, 95\% CI 1.02 to 1.73$)$. No other statistically significant associations were found for any of the mental distress variables (see summary of the results, table 2).

For elite and semielite athletes, the results showed that worries over the financial situation due to COVID-19 was associated with increased risk of both anxiety $(\mathrm{OR}=2.27$, $95 \%$ CI 1.27 to 4.05$)$ and depressive symptoms ( $\mathrm{OR}=2.51$, $95 \%$ CI 1.55 to 4.06 ). Being able to keep daily routines was associated with a decreased risk of symptoms related to depression $(\mathrm{OR}=0.35,95 \% \mathrm{CI} 0.21$ to 0.60$)$ and insomnia ( $\mathrm{OR}=0.57,95 \% \mathrm{CI} 0.36$ to 0.88$)$. Also, perceived positive consequences was associated with a decreased risk of insomnia $(\mathrm{OR}=0.57,95 \%$ CI 0.35 to 0.93$)$,

The perceived ability to cope with the COVID-19 situation was associated with decreased risk of symptoms of anxiety ( $\mathrm{OR}=0.38,95 \%$ CI 0.16 to 0.88$)$, depression $(\mathrm{OR}=0.61,95 \% \mathrm{CI} 0.39$ to 0.94$)$, and insomnia $(\mathrm{OR}=0.62$, $95 \%$ CI 0.42 to 0.92 ) among the Olympic and Paralympic athletes. Also, perceived positive consequences with the current situation $(\mathrm{OR}=0.02,95 \%$ CI 0.01 to 0.40$)$ were associated with a decreased risk of symptoms of eating disorders. Worries over that significant person's risk to die due to COVID-19 was associated with an increased risk of

Table 2 OR $(95 \% \mathrm{Cl})$ for the association between experiences of the COVID-19 situation and mental health for Norwegian Olympic and Paralympic athletes and elite and semielite athletes

\begin{tabular}{llllll}
\hline & Anxiety & Depression & BIS & EDE & Gambling \\
\hline Worry infected & $1.15(0.70$ to 1.89$)$ & $1.11(0.74$ to 1.65$)$ & $1.23(0.87$ to 1.75$)$ & $0.86(0.35$ to 2.08$)$ & $0.61(0.25$ to 1.46$)$ \\
Coping & $0.82(0.54$ to 1.26$)$ & $0.81(0.60$ to 1.10$)$ & $0.82(0.63$ to 1.08$)$ & $1.16(0.54$ to 2.48$)$ & $0.64(0.37$ to 1.12$)$ \\
\hline Economy & $1.65(1.09$ to 2.49$)$ & $1.80(1.33$ to 2.45$)$ & $1.11(0.87$ to 1.43$)$ & $0.94(0.49$ to 1.81$)$ & $0.85(0.50$ to 1.46$)$ \\
\hline Restrictions & $1.07(0.66$ to 1.73$)$ & $1.12(0.80$ to 1.57$)$ & $1.23(0.93$ to 1.62$)$ & $1.41(0.75$ to 2.68$)$ & $0.81(0.44$ to 1.49$)$ \\
\hline Death/illness & $1.23(0.86$ to 1.76$)$ & $1.04(0.79$ to 1.35$)$ & $1.11(0.89$ to 1.39$)$ & $0.75(0.42$ to 1.34$)$ & $1.31(0.81$ to 2.13$)$ \\
\hline Routines & $0.71(0.43$ to 1.17$)$ & $0.53(0.37$ to 0.75$)$ & $0.66(0.48$ to 0.89$)$ & $0.58(0.28$ to 1.20$)$ & $0.97(0.51$ to 1.83$)$ \\
\hline Positive consequences & $0.72(0.43$ to 1.20$)$ & $0.93(0.64$ to 1.37$)$ & $0.91(0.66$ to 1.23$)$ & $0.31(0.15$ to 0.67$)$ & $0.52(0.28$ to 0.98$)$ \\
\hline Positive motivation & $1.49(0.95$ to 2.34$)$ & $0.87(0.65$ to 1.17$)$ & $0.92(0.73$ to 1.16$)$ & $1.00(0.54$ to 1.85$)$ & $1.12(0.70$ to 1.80$)$ \\
\hline Negative motivation & $1.22(0.74$ to 2.00$)$ & $1.05(0.76$ to 1.46$)$ & $1.34(1.02$ to 1.73$)$ & $1.12(0.56$ to 2.24$)$ & $0.78(0.44$ to 1.37$)$ \\
\hline Stress & $1.54(0.97$ to 2.45$)$ & $1.24(0.89$ to 1.72$)$ & $0.99(0.75$ to 1.31$)$ & $1.28(0.68$ to 2.42$)$ & $0.90(0.49$ to 1.67$)$ \\
\hline Test & $1.56(0.53$ to 4.53$)$ & $0.69(0.32$ to 1.46$)$ & $1.27(0.68$ to 2.37$)$ & NA & $3.70(0.45$ to 30.30$)$ \\
\hline Gender & $0.89(0.39$ to 2.03$)$ & $0.83(0.46$ to 1.49$)$ & $0.77(0.48$ to 1.26$)$ & $0.14(0.04$ to 0.57$)$ & $8.73(1.82$ to 42.00$)$ \\
\hline Age & $1.01(0.94$ to 1.08$)$ & $0.96(0.91$ to 1.02$)$ & $1.01(0.97$ to 1.04$)$ & $0.84(0.72$ to 0.99$)$ & $1.01(0.94$ to 1.09$)$
\end{tabular}

BIS, Bergen Insomnia Scale; EDE, Eating Disorder Examination. 
insomnia ( $\mathrm{OR}=1.40,95 \% \mathrm{CI} 1.01$ to 1.95$)$. Last, perceived negative consequences with the COVID-19 situation was associated with an increased risk of insomnia symptoms ( $\mathrm{OR}=1.67,95 \%$ CI 1.10 to 2.53$)$.

\section{Associations between experiences of COVID-19 situation and satisfaction with life}

The results from a linear regression analysis, including all athletes, showed that the independent variables could explain $16.2 \%$ of the variance in satisfaction with life (F $(13,364)=6.60, \mathrm{p}<0.001)$. Positive consequences related to the COVID-19 situation positively associated with satisfaction with life $(B=0.20, p<0.001)$. Also, worries over the financial situation due to COVID-19 ( $\mathrm{B}=-0.25, \mathrm{p}=0.002)$ as well as worries over the length of the COVID-19 restrictions $(\mathrm{B}=-0.11, \mathrm{p}=0.036)$ were negatively associated with satisfaction with life. No other statistically significant associations between the independent and dependent variables were found.

The analysis of the elite and semielite athletes showed that the independent variables could explain $16.9 \%$ of the variance in satisfaction with life $(\mathrm{F}(13,170)=3.86$, $\mathrm{p}<0.001)$. In this group, worries over the financial situation due to COVID-19 were negatively associated with satisfaction with life $(B=-34, p<0.001)$.

For the Olympic and Paralympic athletes, the independent variables explained $13.0 \%$ of the variance in satisfaction with life $(\mathrm{F}(13,180)=3.22, \mathrm{p}<0.001)$. Only positive consequences related to the COVID-19 situation had a statistically significant associated with satisfaction in life $(\mathrm{B}=0.25, \mathrm{p}=0.003)$.

\section{DISCUSSION}

\section{Mental health}

That symptoms of depression and insomnia were the two leading mental health conditions in this study correspond to findings from research involving South African elite athletes. ${ }^{5}$ Both sleep quantity and quality are essential for good mental health; therefore, a higher level of insomnia symptoms is regarded as a concern and could be an early sign of a decline in mental health. ${ }^{14}$ Changes in sleeping patterns can also cause changes in other daily routines.

The psychological impact of the COVID-19 pandemic with its subsequent lockdown and alteration of most people's everyday life is just emerging. A Norwegian study including more than 10000 people from the general, adult population report two to three times higher levels of symptoms of depression and anxiety compared with prepandemic levels, where there also was a marked increase in depression and anxiety levels during the initial stages of the pandemic. ${ }^{13}$ In our results, however, we found that fewer athletes reported high levels of symptoms of anxiety compared with the FIFAPRO data (females: Norwegian athletes $11.3 \%$ vs $18 \%$ FIFAPRO; males $7.7 \%$ vs $16 \%) .{ }^{4}$ These findings were more in line with data from the Swedish population of elite football, ice hockey and handball players, and it was suggested that these differences could be due to cultural differences. ${ }^{6}$

Focusing on the level of depressive symptoms, the results from the current study showed that Norwegian athletes reported higher levels of depression symptoms than FIFAPRO athletes (females: $25.6 \%$ vs $22 \%$ and males: $19.9 \%$ vs $13 \%$ ). They also score higher than the Swedish team players, especially among female athletes. An interesting finding was that within the Norwegian athletes population, the Olympic and Paralympic athletes had lower levels of depression and anxiety symptoms than did elite and semielite athletes, indicating that they coped slightly better with the situation. This group of athletes also have a strong support team available, so it could be that these athletes have more immediate access to expertise and psychological support. In addition, two gender differences occurred where male athletes were more prone to gambling while there were more symptoms of eating disorders among female athletes. However, the prevalence was still at the same level or even lower compared with studies pre-COVID-19. ${ }^{15}$

\section{Associations between experiences of COVID-19 situation and mental health}

The study's second aim was to investigate how COVID-19 specific experiences were associated with mental health symptoms. One significant risk factor for both anxiety as well as depressive symptoms was financial concerns. This result is in line with findings among professional soccer players, especially among those uncertain about their future contracts. ${ }^{4}$ Athletes who were able to keep to their daily routine reported lower levels of depression and were also less likely to have insomnia. These findings are significant because it indicates that assisting athletes with alternative training regimes and continuing a regular sleeping pattern is essential as it might also affect the development of depression and vice versa. This result is also consistent with findings from the general population in Norway, where people who had increased competence to deal with the crisis were associated with less adverse mental health symptoms. ${ }^{14}$

Although it is natural to focus on the pandemic's overwhelmingly negative consequences, we also asked about possible positive consequences of the situation (such as spending more time with your family, recover and relax and practice). We found that athletes who experienced positive consequences reported fewer symptoms of eating disorders and gambling problems. It is essential to understand that some athletes have welcomed a break in a competitive and highly demanding life and that this unexpected break has also been beneficial for some. On the flip side, those who reported that they experienced a flaw in motivation due to the pandemic also reported significantly more insomnia. When we compared Olympic and Paralympic athletes to elite and semielite athletes, we found significant links between reporting financial problems and elevated anxiety and depressive symptoms among the latter. However, symptoms of depression and 
insomnia were lower if they kept their daily routines. If the Olympic and Paralympic athletes felt they coped with the situation, they reported fewer symptoms of anxiety, depression and insomnia. Furthermore, if they experienced positive consequences of the pandemic, lower levels of eating problems were reported. The COVID-19 illness can have a lethal outcome for some patients and Olympic and Paralympic athletes who were concerned about significant others' well-being reported higher levels of insomnia as did those who had a negative outlook on the consequences of the COVID-19 situation. Thus, athletes at different levels seem to experience different challenges regarding mental health and the COVID-19 situation.

\section{Associations between experiences of COVID-19 situation and satisfaction with life}

The focus on mental health among elite athletes has increased immensely in the last four to 5 years, and this has led to a heightened awareness of the topic and improved help to athletes in need. To complement this picture, it is also vital to examine elite athletes' satisfaction with life, even during a pandemic. As we would expect, athletes who experience financial challenges due to the pandemic and who was concerned about the duration of the restriction report lower satisfaction with life, while those who experience positive consequences related to the crises were more satisfied with life. Furthermore, when we looked more closely into the different levels of elite athletes, we found that satisfaction with life among elite and semielite athletes were indeed negatively affected by the financial situation. The uncertainty and possibly more fragile economic situation for this group of athletes is a concern and support need to be considered. For Olympic and Paralympic athletes who experienced positive consequences of the pandemic, however, there was a positive relation to life satisfaction. Where other athletes experienced huge disappointments and concerns, these athletes gained more time to improve their fitness and even heal from injury and therefore had a very different perception of this extreme situation.

\section{Limitations and strengths}

This was a cross-sectional study rather than a prospective study, and there is a need for more studies looking into the overall trend of the mental health status of athletes over time. A major strength of this study is the quality and high response rate, particularly from the Olympiclevel and Paralympic level athletes' sample. This provides us with a unique insight into the mental health status of Norwegian elite athletes that has never been done before. Our results also accentuate the fact that different groups of elite athletes perceive this extreme situation differently, which shows that elite athletes are, in fact, a diverse group.

\section{CONCLUSION}

There is an overall pattern that suggests that financial concern as a direct consequence of the pandemic is one major stressor during uncertain times. Having access to both financial and professional support seems to be essential assets for elite athletes. Our findings suggest that some athletes also welcome the unexpected break this period has caused and have managed to cope well with the situation.

\section{Twitter Anne Marte Pensgaard @ampensgaard}

Acknowledgements The authors are thankful to all the elite athletes who participated in the study.

Contributors $\mathrm{THO}$ and AMP proposed the initial idea. All authors contributed to the conception of the work or the acquisition and interpretation of data. All authors critically revised the manuscript and approved the final version. All authors contributed to the conception of the work. Al conducted the analyses, and all authors contributed to the acquisition and interpretation of data. AMP wrote the initial draft. All authors critically revised the manuscript and approved the final version.

Funding 'The Mental Health in Elite Sport Study' is supported by a grant from the Norwegian Olympic Training Centre, Olympiatoppen.

Competing interests None declared.

Patient and public involvement Patients and/or the public were involved in the design, or conduct, or reporting, or dissemination plans of this research. Refer to the Methods section for further details.

\section{Patient consent for publication Not required.}

Ethics approval Written informed consent was acquired prior to inclusion and approvals from the Regional Committee for Medical Research Ethics (0slo) REC South-East nr 28432.

Provenance and peer review Not commissioned; externally peer reviewed.

Data availability statement Data are available on reasonable request. The data include highly elite and well-known athletes.

Open access This is an open access article distributed in accordance with the Creative Commons Attribution Non Commercial (CC BY-NC 4.0) license, which permits others to distribute, remix, adapt, build upon this work non-commercially, and license their derivative works on different terms, provided the original work is properly cited, appropriate credit is given, any changes made indicated, and the use is non-commercial. See: http://creativecommons.org/licenses/by-nc/4.0/.

\section{ORCID iDs}

Anne Marte Pensgaard http://orcid.org/0000-0003-4690-9888

Tom Henning Oevreboe http://orcid.org/0000-0003-4965-1018

Andreas Ivarsson http://orcid.org/0000-0002-8987-5975

\section{REFERENCES}

1 Reardon $\mathrm{CL}$, Hainline B, Aron CM, et al. Mental health in elite athletes: international Olympic Committee consensus statement (2019). Br J Sports Med 2019;53:667-99.

2 Sarto F, Impellizzeri FM, Spörri J, et al. Impact of potentia physiological changes due to COVID-19 home confinement on athlete health protection in elite sports: a call for awareness in sports programming. Sports Med 2020;50:1417-9.

3 Reardon CL, Bindra A, Blauwet C, et al. Mental health management of elite athletes during COVID-19: a narrative review and recommendations. Br J Sports Med 2020. doi:10.1136/ bjsports-2020-102884. [Epub ahead of print: 23 Sep 2020]

4 Gouttebarge V, Ahmad I, Mountjoy M, et al. Anxiety and depressive symptoms during the COVID-19 emergency period: a comparative cross-sectional study in professional football. Clin J Sport Med 2020;00:1-7.

5 Pillay L, Janse van Rensburg DCC, Jansen van Rensburg A, Rensburg Jvan, et al. Nowhere to hide: the significant impact of coronavirus disease 2019 (COVID-19) measures on elite and semielite South African athletes. J Sci Med Sport 2020;23:670-9.

6 Håkansson A, Jönsson C, Kenttä G. Psychological distress and problem gambling in elite athletes during COVID-19 Restrictions-A 
web survey in top Leagues of three sports during the pandemic. Int J Environ Res Public Health 2020;17. doi:10.3390/ijerph17186693. [Epub ahead of print: 14 Sept 2020].

7 Strand BH, Dalgard OS, Tambs K, et al. Measuring the mental health status of the Norwegian population: a comparison of the instruments SCL-25, SCL-10, SCL-5 and MHI-5 (SF-36). Nord J Psychiatry 2003;57:113-8.

8 Pallesen S, Bjorvatn B, Nordhus IH, et al. A new scale for measuring insomnia: the Bergen insomnia scale. Percept Mot Skills 2008;107:691.

9 Prnjak K, Mitchison D, Griffiths S, et al. Further development of the 12-Item EDE-QS: identifying a cut-off for screening purposes. BMC Psychiatry 2020;20:1-7.

10 Ferris J, Wynne H. The Canadian problem gambling index: final report. Canadian Consortium for Gambling Research, 2001.

11 Diener E, Emmons RA, Larsen RJ, et al. The satisfaction with life scale. J Pers Assess 1985;49:71-5.
12 Clench-Aas J, Nes RB, Dalgard OS, et al. Dimensionality and measurement invariance in the satisfaction with life scale in Norway. Qual Life Res 2011;20:1307-17.

13 Ebrahimi O, Hoffart A, Johnson SU. The mental health impact of non-pharmacological interventions aimed at impeding viral transmission during the COVID-19 pandemic in a general adult population and the factors associated with adherence to these mitigation strategies. PsyArXiv 2020.

14 Walsh NP, Halson SL, Sargent C, et al. Sleep and the athlete: narrative review and 2021 expert consensus recommendations. $\mathrm{Br} \mathrm{J}$ Sports Med 2020. doi:10.1136/bjsports-2020-102025. [Epub ahead of print: 03 Nov 2020].

15 Sundgot-Borgen J, Torstveit MK. Prevalence of eating disorders in elite athletes is higher than in the general population. Clin J Sport Med 2004;14:25-32. 